\title{
Caspase-activated ROCK-1 allows erythroblast terminal maturation independently of cytokine-induced Rho signaling
}

\author{
A-S Gabet ${ }^{1}$, S Coulon ${ }^{1}$, A Fricot ${ }^{1}$, J Vandekerckhove ${ }^{1}$, Y Chang ${ }^{2,3}$, J-A Ribeil ${ }^{1}$, L Lordier ${ }^{2,3}$, Y Zermati ${ }^{4}$, V Asnafi ${ }^{1}$, Z Belaid ${ }^{1}$, N Debili ${ }^{2,3}$, \\ W Vainchenker ${ }^{2,3}$, B Varet ${ }^{1,5}, 0$ Hermine ${ }^{\star, 1,5}$ and G Courtois ${ }^{\star, 1}$
}

Stem cell factor (SCF) and erythropoietin are strictly required for preventing apoptosis and stimulating proliferation, allowing the differentiation of erythroid precursors from colony-forming unit- $E$ to the polychromatophilic stage. In contrast, terminal maturation to generate reticulocytes occurs independently of cytokine signaling by a mechanism not fully understood. Terminal differentiation is characterized by a sequence of morphological changes including a progressive decrease in cell size, chromatin condensation in the nucleus and disappearance of organelles, which requires transient caspase activation. These events are followed by nucleus extrusion as a consequence of plasma membrane and cytoskeleton reorganization. Here, we show that in early step, SCF stimulates the Rho/ROCK pathway until the basophilic stage. Thereafter, ROCK-1 is activated independently of Rho signaling by caspase-3-mediated cleavage, allowing terminal maturation at least in part through phosphorylation of the light chain of myosin II. Therefore, in this differentiation system, final maturation occurs independently of SCF signaling through caspase-induced ROCK-1 kinase activation.

Cell Death and Differentiation (2011) 18, 678-689; doi:10.1038/cdd.2010.140; published online 12 November 2010

Erythropoiesis is a multistep process that occurs in the bone marrow and involves the sequential formation of proerythroblasts - basophilic, polychromatic and orthochromatic erythroblasts and enucleated reticulocytes. Terminal erythroid differentiation is characterized by hemoglobin synthesis and major morphological changes, including chromatin condensation, cell size reduction and finally, nucleus extrusion to generate reticulocytes that enter in the blood circulation. ${ }^{1}$ This differentiation process involves the transcription factor GATA-1, ${ }^{2,3}$ which positively regulates promoters of erythroid genes such as glycophorin $A$, the erythropoietin receptor (EPO-R) and hemoglobin chains.

Some features of terminal differentiation of erythroid cells are similar to features associated with apoptosis, such as chromatin condensation, organelle loss and membrane remodeling. Along with others, we have previously demonstrated that transient activation of effector caspases at the basophilic stage is required for terminal erythroid maturation. $^{4-6}$ Caspases induce cleavage of several proteins involved in the nuclear structural changes observed during terminal erythroid differentiation, such as lamin B, acinus or PARP. $^{7}$ In contrast, GATA-1, a target of caspases during apoptosis, is not cleaved during differentiation, allowing expression of erythroid genes and survival. This protection of GATA-1 from cleavage by caspases is explained by the translocation into the nucleus at the onset of caspase activation of the chaperone protein HSP70. At this stage, HSP70 interacts physically with GATA-1 resulting in protection against caspase cleavage. ${ }^{8}$ Identification of each caspase substrate might be helpful for understanding the mechanisms that determine the fate (differentiation versus apoptosis) of erythroid cells in different physiological or pathological conditions.

Erythropoiesis is regulated by a number of growth factors. Two of these growth factors are critical and have distinct and non-redundant functions, namely the C-KIT ligand or stem cell factor $(\mathrm{SCF})^{9}$ and erythropoietin (EPO). ${ }^{10}$ SCF induces an increase in cell survival and expansion of BFU-E and colonyforming unit (CFU)-E, and slows down the differentiation of these cells toward the basophilic stage. ${ }^{10,11}$ Thereafter, cell-surface c-KIT expression is down modulated. ${ }^{12}$ EPO, which acts synergistically with SCF from late BFU-E until the basophilic stage is strictly required for preventing apoptosis and stimulating proliferation, allowing differentiation of erythroid progenitors and precursors, from CFU-E until the polychromatophilic stage. ${ }^{13}$ In contrast, terminal maturation from polychromatophilic erythroblasts to reticulocytes occurs independently of signaling by these two cytokines.

This cytokine independence of terminal maturation of erythroid precursors is a peculiar phenomenon that may depend in vivo on integrins signaling for erythroid progenitors proliferation. However, it remains to be understood by which mechanisms orthochromatic erythroblasts undergo cytoskeleton reorganization, specifically contractile actin ring

\footnotetext{
${ }^{1}$ Université René Descartes Paris V, CNRS UMR 8147 et IFR Necker, Paris, France; ${ }^{2}$ INSERM, U1009, Pavillon de Recherche 1, Institut Gustave Roussy, Villejuif, France; ${ }^{3}$ Université Paris XI, Institut Gustave Roussy, Villejuif, France; ${ }^{4}$ Institut Cochin, Université René Descartes Paris V, Paris, France and ${ }^{5}$ Department of Hematology and Centre de Référence des Mastocytoses, Faculté de Médecine et Université René Descartes, Assistance Publique, Hôpitaux de Paris, Paris, France *Corresponding author: G Courtois or O Hermine, Hôpital Necker- CNRS UMR 8147, 161 rue de Sèvres, 75743- Paris, Cedex 15, France. Tel: 33144490675 ; Fax: 331444906 76; E-mail: genevieve.courtois@parisdescartes.fr or ohermine@gmail.com Keywords: erythropoiesis; ROCK-1; caspases

Abbreviations: EPO, erythropoietin; SCF, stem cell factor; BFU-E, Burst-Forming Unit erythroid; IL3, interleukin 3; GPA, glycophorin A

Received 22.4.10; revised 14.9.10; accepted 05.10.10; Edited by R De Maria; published online 12.11.10
} 
formation for extrusion of pycnotic nucleus, a process highly dependent on kinases signaling.

Small GTPases of the Rho family (RhoA, Rac and Cdc42) transduce signals from receptors at the plasma membrane to the actin and microtubule cytoskeleton as well as to kinase cascades that regulate cell morphology and many different processes such as motility and cell cycle progression. On activation, Rho proteins exchange GDP for GTP, transduce signals to downstream effector proteins and finally return to the inactive GDP-bound form by hydrolyzing the bound GTP. ${ }^{14-16}$ Whereas RhoA, Rac1 or Cdc42 are ubiquitously expressed, Rac2 expression is confined to the hematopoietic compartment. ${ }^{17}$ Rac GTPases are dynamic regulators of erythrocyte cytoskeleton organization ${ }^{18}$ and are required in mice for early erythropoietic expansion in the bone marrow but not in the spleen. Rac1 and Rac2 deficiency may disrupt signaling downstream of SCF and IL3 to affect bone marrow erythropoiesis. By contrast, the splenic microenvironment can circumvent this deficiency. ${ }^{19}$ Rac GTPases are required for the formation of the contractile actin ring and enucleation of mouse fetal erythroblasts. ${ }^{20}$ In contrast, the role of RhoA has not been investigated in erythroblasts.

Two isoforms of a serine/threonine kinase (Rho-associated kinases ROCK-1 and ROCK-2) have been identified as effectors of Rho. In non-muscle cells, ROCK proteins regulate several cellular functions downstream of Rho and control actin cytoskeleton assembly and cell contractility. ${ }^{21}$ Thereby, they contribute to several physiological processes by phosphorylation of various substrates such as MLC2 (myosin light chain 2) phosphatase, LIM kinase and ezrin-radixin-moesin proteins. Phosphorylation of the regulatory MLC of myosin II induces its interaction with actin, which thereby activates myosin ATPase and results in enhanced cell contractility. ${ }^{22}$ Both ROCK-1 and ROCK-2 regulate MLC2 phosphorylation either directly by phosphorylating MLC2 on Ser19 or indirectly by inhibiting MLC phosphatase. ${ }^{23}$ Cleavage of the C-terminal domain of ROCK proteins results in the generation of a constitutively active kinase. This occurs in vivo during the execution phase of apoptosis, when ROCK-1 but not ROCK-2 is cleaved by caspase- 3 , inducing membrane blebbing. ${ }^{24,25}$

As terminal erythroid differentiation is associated with actin filaments contractility and caspase activation, we wondered (i) whether the Rho/ROCK signaling pathway could be involved in differentiation of erythroid progenitors (ii) whether ROCK-1 could be a caspase target. In this study, we show that inhibition of ROCK-1 but not Rho activity impairs erythroblasts terminal maturation. In addition, our data reveal that the Rho pathway is primarily activated by SCF/c-KIT during the early stage of erythroid precursors maturation. Caspase-3mediated cleavage of ROCK-1 allows constitutive activation from the basophilic stage to mature cells, at the time of extinction of the c-KIT/Rho pathway. Therefore, we identified an additional role of caspase activation during erythroid differentiation, allowing cytokine independency.

\section{Results}

Rho is primarily activated through the SCF/c-KIT pathway. Erythroid cells were generated with a two-step amplification culture system as described in the Materials and Methods section. In this culture system, differentiation was asynchronous and most of the cells remained immature until day 8 , after which polychromatic and orthochromatic erythroblasts were gradually generated. In these conditions, the onset of caspase-3 activation occurred at day 7-8.

As ROCK proteins are classically activated by GTP-bound Rho, we analyzed Rho expression during erythroid differentiation. As compared with $\mathrm{HSC} 70$, used as a control for loading, the level of Rho protein decreased at the onset of caspase-3 activation (Figure 1a). Pull-down analyses were performed at day 4 to determine Rho activity before the onset of caspase-3 activation. GST-RBD (Rhotekin Rho-binding domain) was used to pull down the active Rho-GTP form. For this purpose, CD36 cells were cytokine deprived for $8 \mathrm{~h}$ then stimulated by SCF, EPO or SCF + EPO for 5 to $30 \mathrm{~min}$. Rho activity peaked at $5 \mathrm{~min}$ (data not shown) and was strongly activated by SCF and to a lesser extent by EPO (Figure 1b). EPO and SCF had an additive effect indicating that SCF/EPO signaling is involved in Rho activation at this stage of erythroid differentiation. In contrast, when pull-down analyses were performed at day 10 (after the onset of caspase-3 activation), Rho activity was equivalent to residual activity after EPO and SCF starvation for $8 \mathrm{~h}$. Therefore, we could conclude that Rho is primarily activated through SCF stimulation as long as C-KIT is expressed. Thus, after the onset of caspase activation, Rho can no longer be activated because c-KIT is down modulated (Figure 1c). ${ }^{12}$

day $\begin{array}{llll}4 & 6 & 8 & 10\end{array}$
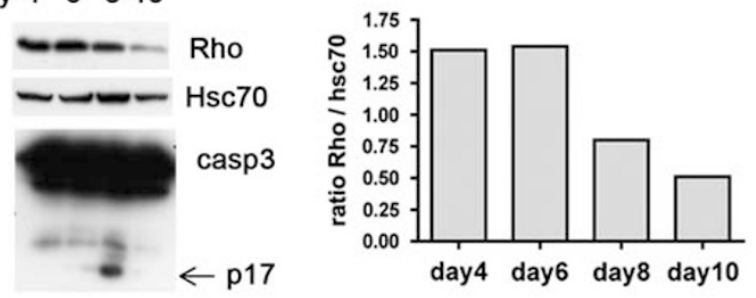

b

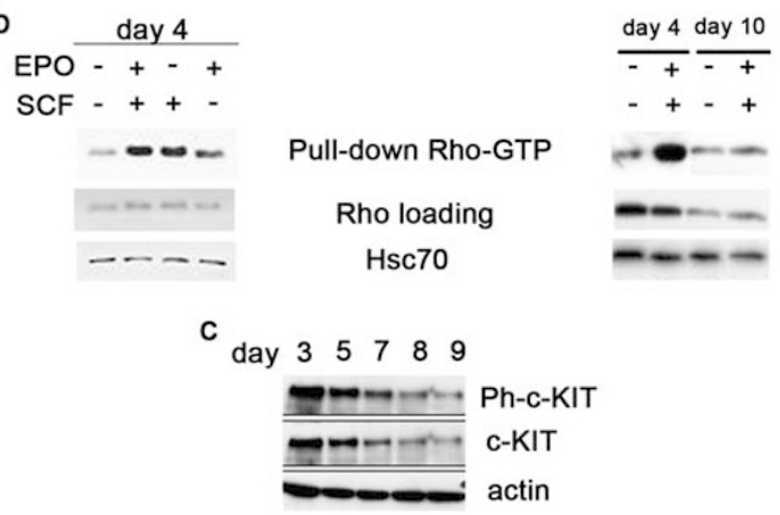

Figure 1 Rho is primarily activated through SCF stimulation. Immunoblots were performed from $\mathrm{CD} 36$ lysates at indicated times in the presence of cytokines, or with 8-h deprivation of growth factors. HSC70 or actin are shown as loading control. (a) Rho expression decreased after the onset of caspases activation as shown by western blot quantification showing the Rho/HSC70 ratio. (b) Pull-down RBD-bound Rho indicates that Rho is primarily activated by SCF before the onset of caspase activation (day 4) but not after the onset of caspase activation (day 10). (c) Immunoblots indicate that $120-\mathrm{kDa}$ c-KIT is down modulated at the onset of caspase-3 activation 


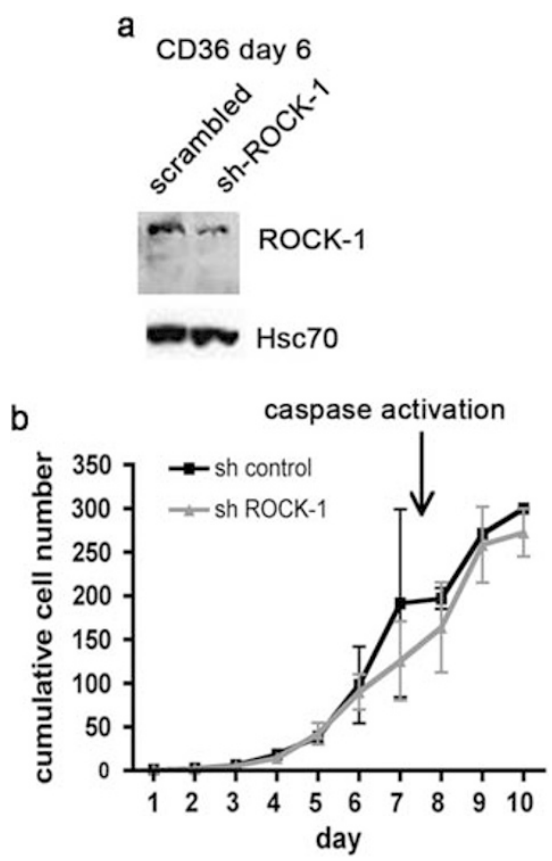

Figure 2 ROCK-1 inhibition is not involved in erythroblasts proliferation. CD36 cells infected by scrambled or shRNA lentiviruses targeting ROCK-1 were cultured as described in the Materials and Methods section. (a) Immunoblot analysis performed at day 6 of the CD36 culture shows a 47\% reduction in ROCK- 1 protein level in ROCK-1 shRNA-infected cells. (b) Viable cells were assessed daily by Trypan blue staining at indicated times. The graph indicates the cumulative cell number. Means of cumulative cell number of five representative experiments are shown

Effect of ROCK-1 inhibition on cell proliferation. The requirement for ROCK function for proliferation in numerous cell types has previously been demonstrated. ${ }^{26}$ We therefore monitored the proliferation of erythroid progenitors in which ROCK-1 activity was inhibited using RNA interference. For this purpose, CD $34^{+}$cells isolated from cord blood were infected as described with lentiviruses encoding short hairpin RNA (shRNA) targeting ROCK-1 mRNA. A scrambled shRNA sequence was used as a control. Western blots performed at day 6 of the CD36 lysates from selected GFP ${ }^{+}$ cells showed a $47 \%$ reduction in ROCK-1 protein level (Figure 2a) demonstrating the efficacy of the shRNA.

The culture condition that we used allowed massive proliferation of the erythroid progenitors with a 300- to 400fold amplification at day 10 . Analyses using annexin $\mathrm{V}$ labeling along with propidium iodide (PI) staining showed that ROCK-1 inhibition did not significantly increase apoptosis in the culture except at the onset of caspase activation (Supplementary Information 1). ROCK-1 shRNA-infected cells had a similar proliferation rate to cells in the control culture (Figure $2 \mathrm{~b}$ ). Therefore, we could conclude that ROCK-1 is not involved in erythroblast proliferation.

ROCK-1 inhibition impairs terminal maturation of erythroblasts. To investigate the role of ROCK-1 in differentiation of erythroid progenitors, we first used Y-27632, a cell-permeable compound that is specific and efficient for inhibition of the activity of both ROCK-1 and ROCK-2. ROCK inhibitor Y-27632 was added at a concentration of $10 \mu \mathrm{M}$ from day 0 to 12 of the CD36 culture. Terminal differentiation was analyzed by examining the morphologic features of the erythroid cells using May-Grünwald-Giemsa staining at serial time intervals in the presence or absence of Y-27632. Erythroid maturation was also evaluated by flow cytometric analysis of FSC-SSC cell distribution as described in the Materials and Methods section (Figure $3 \mathrm{~A}$ ) and by cell-surface C-KIT/GPA expression that allowed quantitative assessment of the maturation stage of differentiating erythroblasts. By day 6 , the majority of erythroid cells are $\mathrm{KIT}^{\text {pos }} \mathrm{GPA}^{\text {int }}$. At the onset of caspases activation, C-KIT is down modulated and the ratio of $\mathrm{KIT}^{\text {neg }} \mathrm{GPA}{ }^{\text {high }}$ is progressively increased (Figures $3 \mathrm{~b}$ and $\mathrm{c}$ ).

At day 12 of the control culture, a mean of $25.8 \% \pm 1.3$ of the cells exhibited a mature phenotype (polychromatic and orthochromatic erythroblasts) as identified by morphological analyses. In the Y-27632 treated culture, multinucleate cells appeared at day $3(0.5-2 \%)$. However, the proportion of these cells was low compared with $25-30 \%$ observed with blebbistatin, a selective inhibitor of myosin II ATPase activity (data not shown), suggesting that ROCK does not have a critical role in cytokinesis of early erythroblasts. At day 12 , the proportion of mature cells was dramatically decreased in the presence of the ROCK inhibitor with a mean of $12.5 \% \pm 0.9$ (Figure 4ai). FSC-SSC cell distribution in flow cytometric analysis, as described Figure 3 , also indicated that the Y-27632 treatment significantly increased the proportion of immature cells $(39.9 \% \pm 1.6$ versus $20.3 \% \pm 4.2$ in controls within gate $\mathrm{C}$ ) and decreased the proportion of mature cells $(11.9 \% \pm 1.1$ versus $22.8 \% \pm 3.6$ in controls within gate $\mathrm{A}$ and $4.3 \% \pm 1$ versus $6.3 \% \pm 0.8$ in controls within gate $B$ ) (Figure 4aii).

Similar results were observed when the ROCK inhibitor was added at the onset of caspase activation from day 7 to 12 as assessed by morphological analyses $(22.5 \% \pm 0.8$ of mature cells versus $29.7 \% \pm 1.1$ in controls) (Figure $4 \mathrm{bi}$ ), and FSCSSC analyses $(36.3 \% \pm 3.6$ versus $24.9 \% \pm 2.9$ in controls within gate $C, 4.2 \% \pm 1.5$ versus $6.2 \% \pm 1.2$ in controls within gate $B$ and $10.9 \% \pm 1.4$ versus $17.2 \% \pm 1.9$ in controls within gate A) (Figure 4bii).

Erythroid maturation was also evaluated by GPA and c-KIT cell-surface expression. Two populations with specific staining characteristics were defined using flow cytometry. The populations $c-K I T^{\text {neg }}$ GPA $^{\text {high }}$ and $c-K_{1}{ }^{\text {pos }}$ GPA $^{\text {int }}$ corresponded respectively to mature and immature cells (Figure $3 \mathrm{C}$ ). The ROCK inhibitor added from day 0 to 10 or from day 7 to 10 of the CD36 culture significantly decreased the proportion of $\mathrm{C}-\mathrm{KIT}^{\text {neg }}$ GPA $^{\text {high }}$ cells $(44.65 \pm 1.52$ in controls, versus $25.50 \pm 3.03$ in the Y-27632 treated culture, versus $32.20 \pm 3.03$ when the ROCK inhibitor was added from day 7) and increased the proportion of C-KIT ${ }^{\text {pos }}$ GPA $^{\text {int }}$ cells $(26.35 \pm 0.45$ in controls, versus $37.40 \pm 1.44$ in the Y-27632 treated culture, versus $31.50 \pm 3.46$ when the ROCK inhibitor was added from day 7 ) (Figure 4biii).

Then, to discriminate between ROCK-1 and ROCK-2 function, we examined the effect of ROCK-1 knock down by RNA interference. Although shRNA partially inhibited 
ROCK-1 expression at day 6 (Figure 2a), a significant decrease in cell maturation was observed in ROCK-1 shRNA-infected culture. At day 12 , a mean of $9.5 \% \pm 2.1$ of the cells exhibited a mature phenotype versus $22.4 \% \pm 2.5$ in controls (Figure 4ci). FSC-SSC cell distribution analysis indicated that ROCK-1 knock-down significantly increased the proportion of immature cells $(44.2 \% \pm 3.4$ versus $38.9 \% \pm 2.9$ in controls within gate $C)$ and decreased the proportion of mature cells $(8.8 \% \pm 1.5$ versus $14.4 \% \pm 0.2$ in controls within gate $A$, and $2.2 \% \pm 0.5$ versus $7.9 \% \pm 2.4$ in controls within gate $\mathrm{B}$ ) (Figure 4cii). The ratio of GPA ${ }^{\text {high }}$ cells was also decreased in ROCK-1 shRNAinfected cells $(27.45 \pm 2.39$ versus $38.30 \pm 2.20$ in scrambled) (Figure 4ciii). Taken together, these results suggest that ROCK1 is involved in terminal maturation, which occurs after the onset of caspase activation.
ROCK-1 is activated independently of Rho. We next investigated the mechanism of ROCK-1 activation. To determine whether ROCK-1 is dependent on Rho activity during the late stage of maturation, we overexpressed a dominant-negative form of RhoA by infecting CD36 cells with the MIGR-Rho-N19 retrovirus. To evaluate the functionality of the construct, pull-down analyses were performed with EPO-stimulated CD36 cells overexpressing the MIGR-RhoN19 construct, which inhibited Rho activity (Figure 5a). Terminal differentiation was not significantly impaired when the CD36 cells were infected with the MIGR-Rho-N19 retrovirus compared with the MIGR-GFP control retrovirus as shown by morphological (Figure $5 \mathrm{~b}$ ) and FACS analyses (Figure $5 \mathrm{c}$ ). This is consistent with our results showing that Rho was not activated at this stage of maturation (Figure $1 \mathrm{~b}$ ).

A
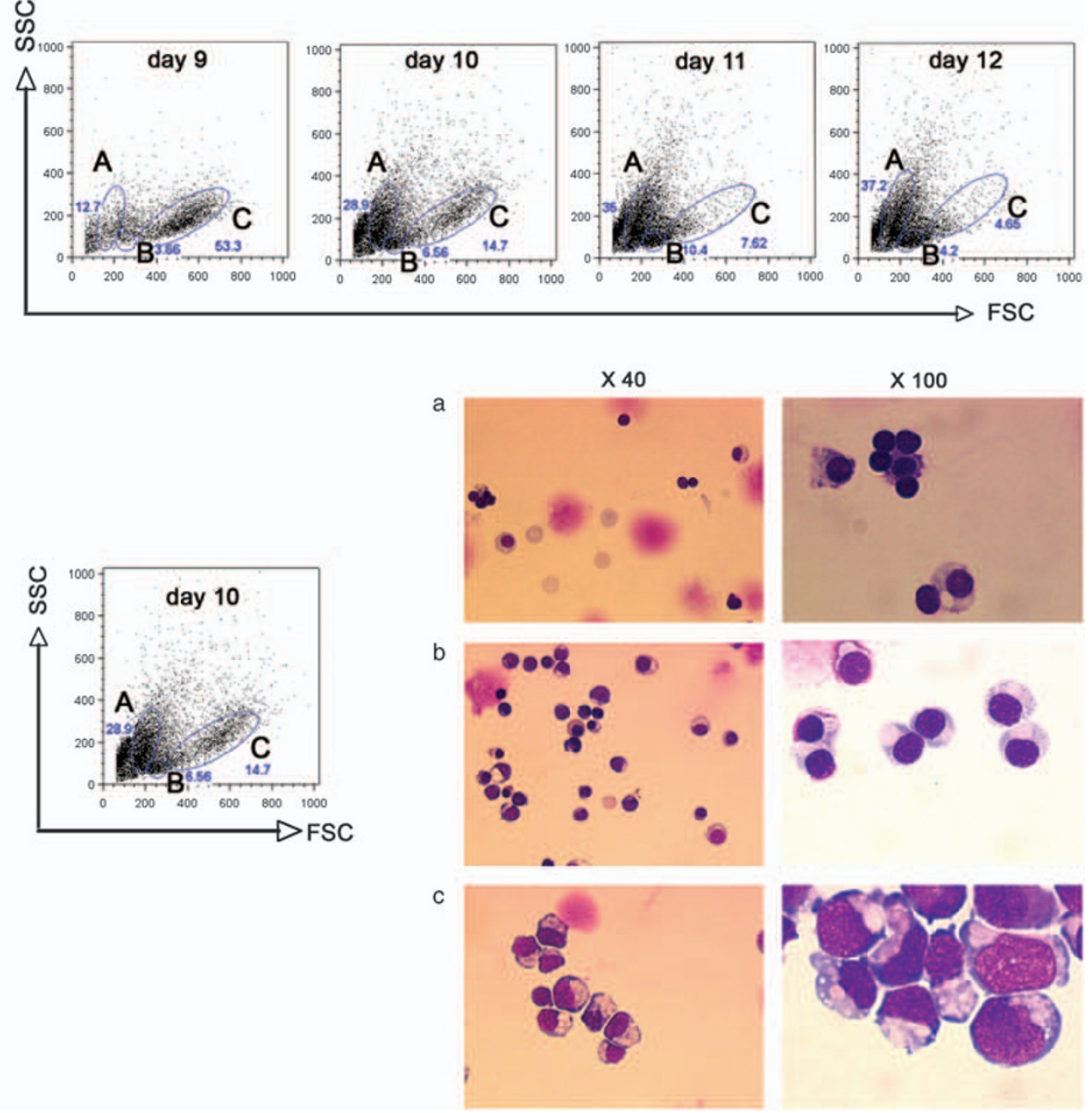

Figure 3 Flow cytometric analysis of differentiating erythroblasts. (A) CD36 cells cultured as described were analyzed from day 9 to 12 of the culture by forward light scatter and side scatter flow cytometry density plots after dead cells (PI-positive) and debris (low forward scatter) exclusion as described in the Materials and Methods section. Regions A, B and C were defined and cells from each population were sorted and analyzed morphologically with PLFluotar $\times 40$ and $\times 100$ oil objectives after May-Grünwald-Giemsa staining. Proerythroblasts were identified in gate $\mathrm{C}$, polychromatic and orthochromatic erythroblasts in gate $\mathrm{B}$ and a mix of orthochromatic erythroblasts, reticulocytes and nuclei were present in gate A. (B) Flow cytometric dot plots from CD36 cells cultured as described, representative of three experiments and analyzed from day 1 to 10 of the culture. Cells were double labeled for C-KIT-APC and GPA-PE as described in the Materials and Methods section. The relative number of cells in each region is indicated. (C) Left panel: flow cytometric dot plots from day 10 CD36. Regions $A, B$ and $C$ were selected as indicated. The right panels show the flow cytometric dot plots for $\mathrm{C}-\mathrm{KIT}$ and GPA for cells derived from each region as described in B. These results show that the majority of the cells from regions A and B are C$\mathrm{KIT}^{\text {neg }} \mathrm{GPA}{ }^{\text {high }}$ and the majority of the cells from region $\mathrm{C}$ are $\mathrm{C}-\mathrm{KIT}^{\text {pos }} \mathrm{GPA} \mathrm{A}^{\text {int }}$ 


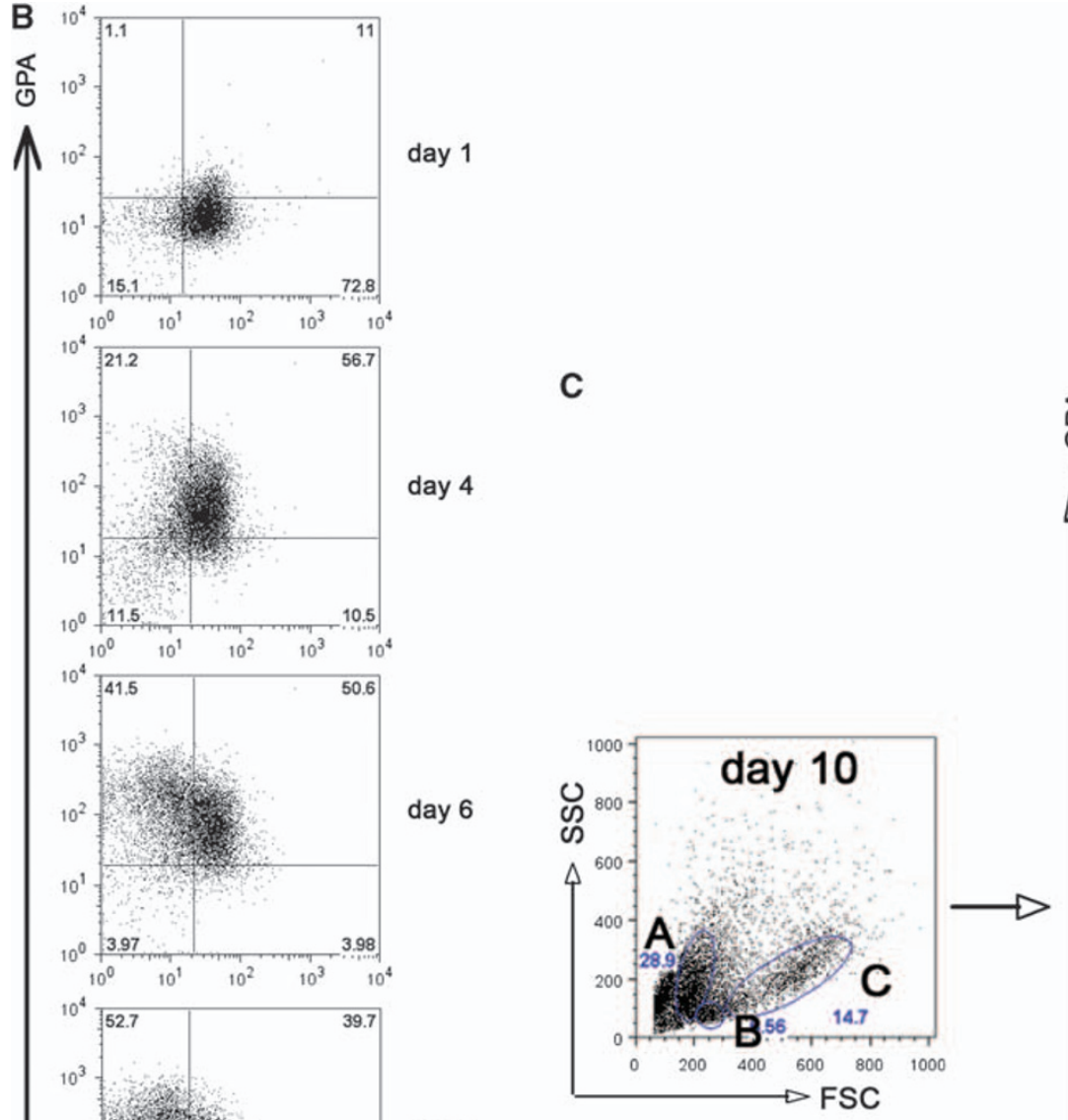

day 8

day 10

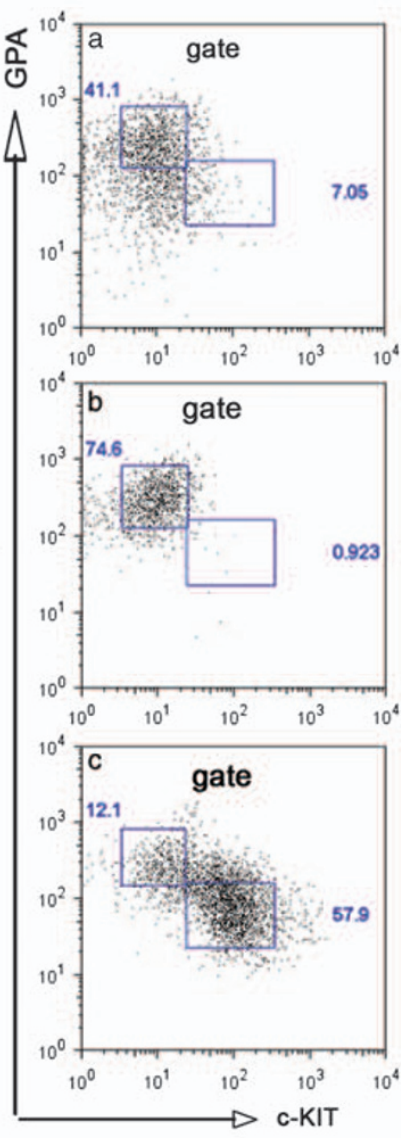

Figure 3 Continued

ROCK-1 is activated by caspase-3 cleavage. As caspase3 was shown to constitutively activate ROCK-1 during apoptosis in many cells, whereas ROCK-2 cannot be cleaved by caspase-3, western blotting of whole-cell lysates was performed at several time intervals to evaluate the possible activation of ROCK-1 through caspase-3 cleavage during erythroid differentiation. In this in vitro culture system, the percentage of cells undergoing apoptosis could reach $15-20 \%$ at the end of differentiation. To discriminate differentiation from apoptotic ROCK-1 cleavage, day 10 annexin V- and PI-positive cells were excluded by cell sorting before cell lysis. By probing with a ROCK-1-specific antibody, in addition to the full-length $160-\mathrm{kDa}$ protein, a $130-\mathrm{kDa}$ fragment was detected in non-apoptotic cells from the onset of caspase-3 activation until the end of differentiation (Figure 6a). Similarly, treatment of the culture during the second step of differentiation with z-VAD-fmk at a dose of $150 \mu \mathrm{M}$, which inhibited terminal erythroid differentiation, ${ }^{4}$ abolished the ROCK- 1 cleavage. As a control, the same $130-\mathrm{kDa}$ cleavage product was present after overnight EPO starvation, strongly suggesting that this truncated ROCK-1 corresponds to the fragment 

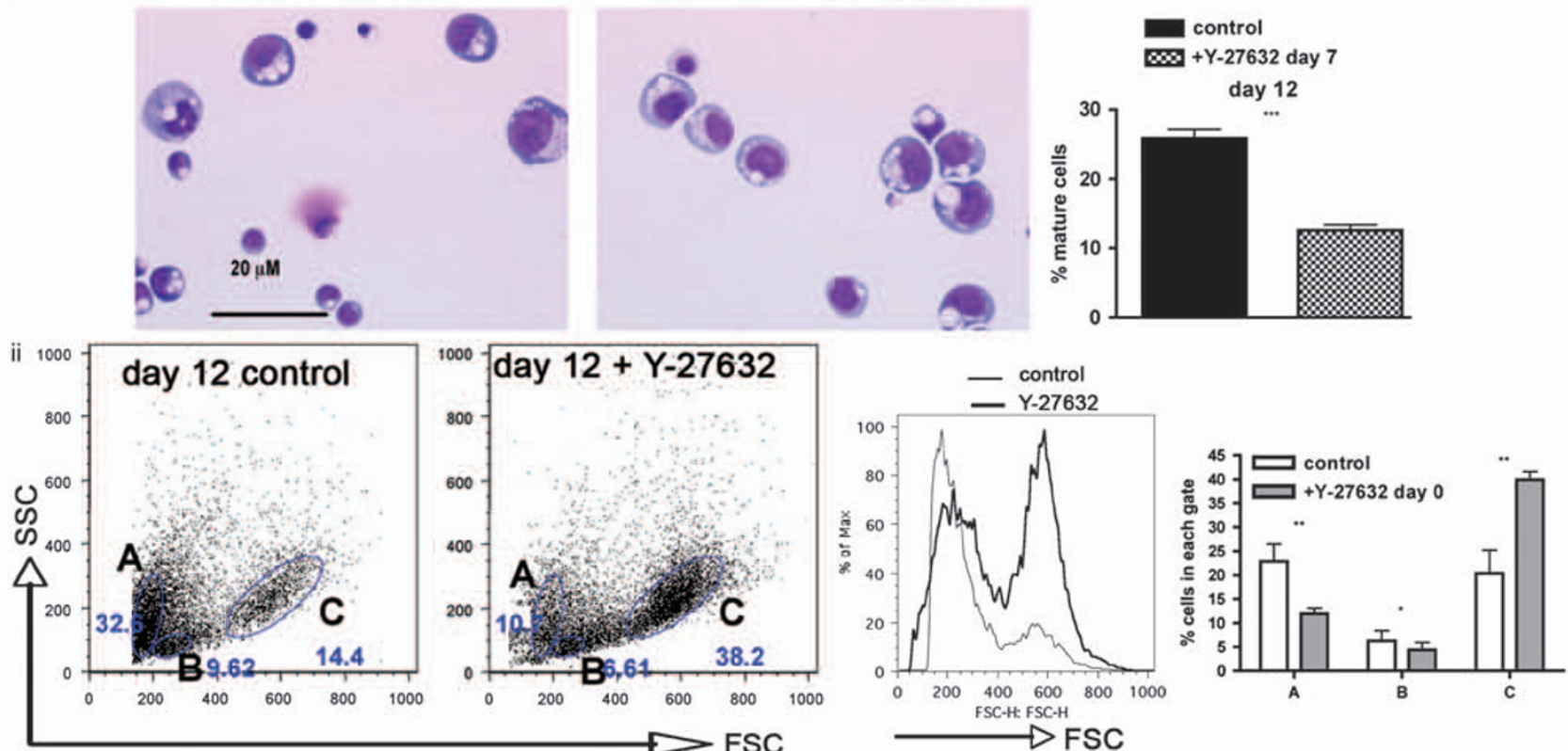

b

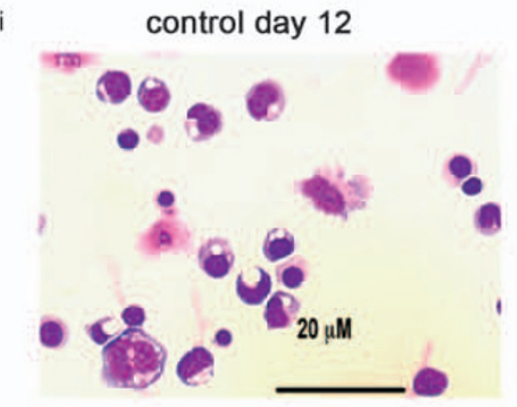

day $12+\mathrm{Y}-27632$ day 7
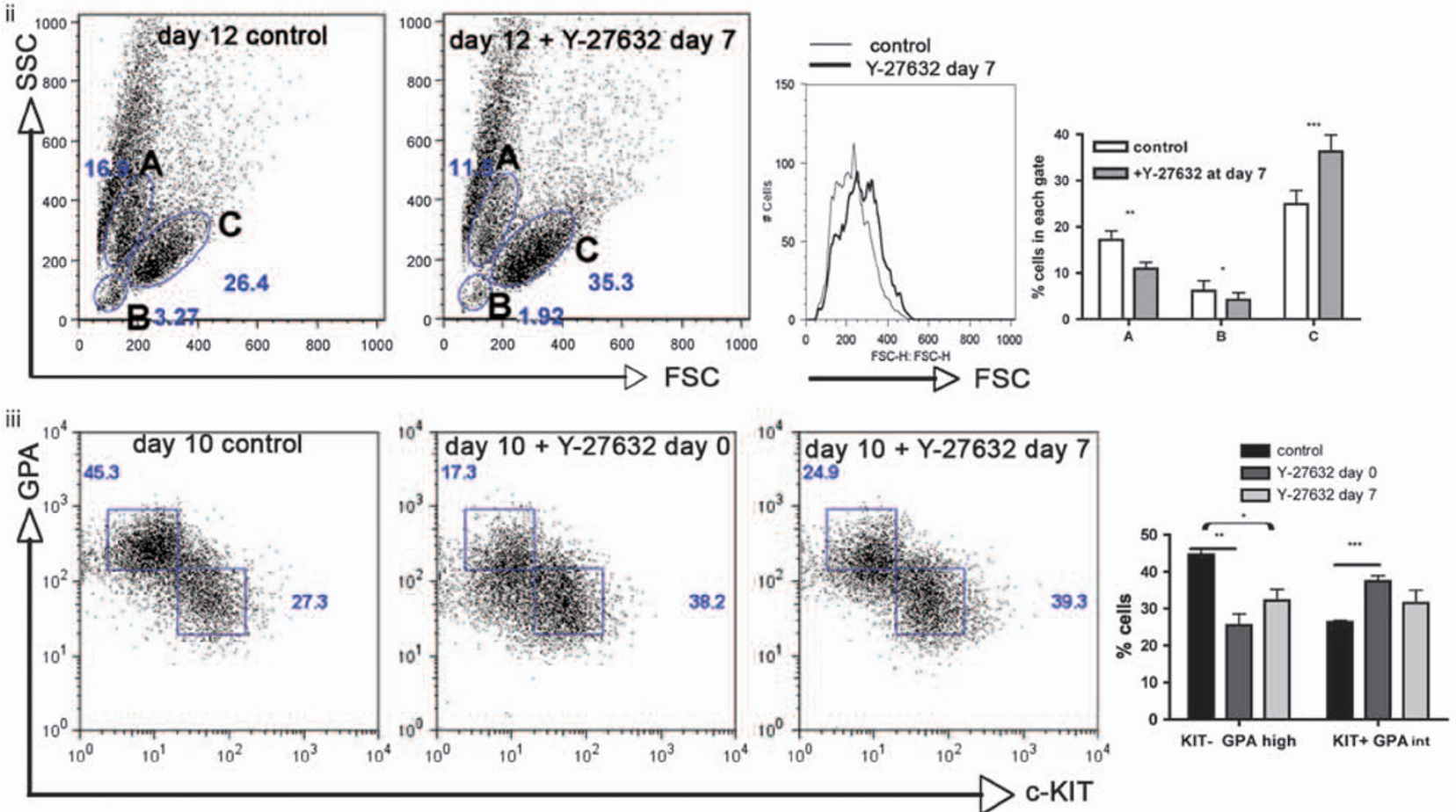

Figure 4 Continued 
C
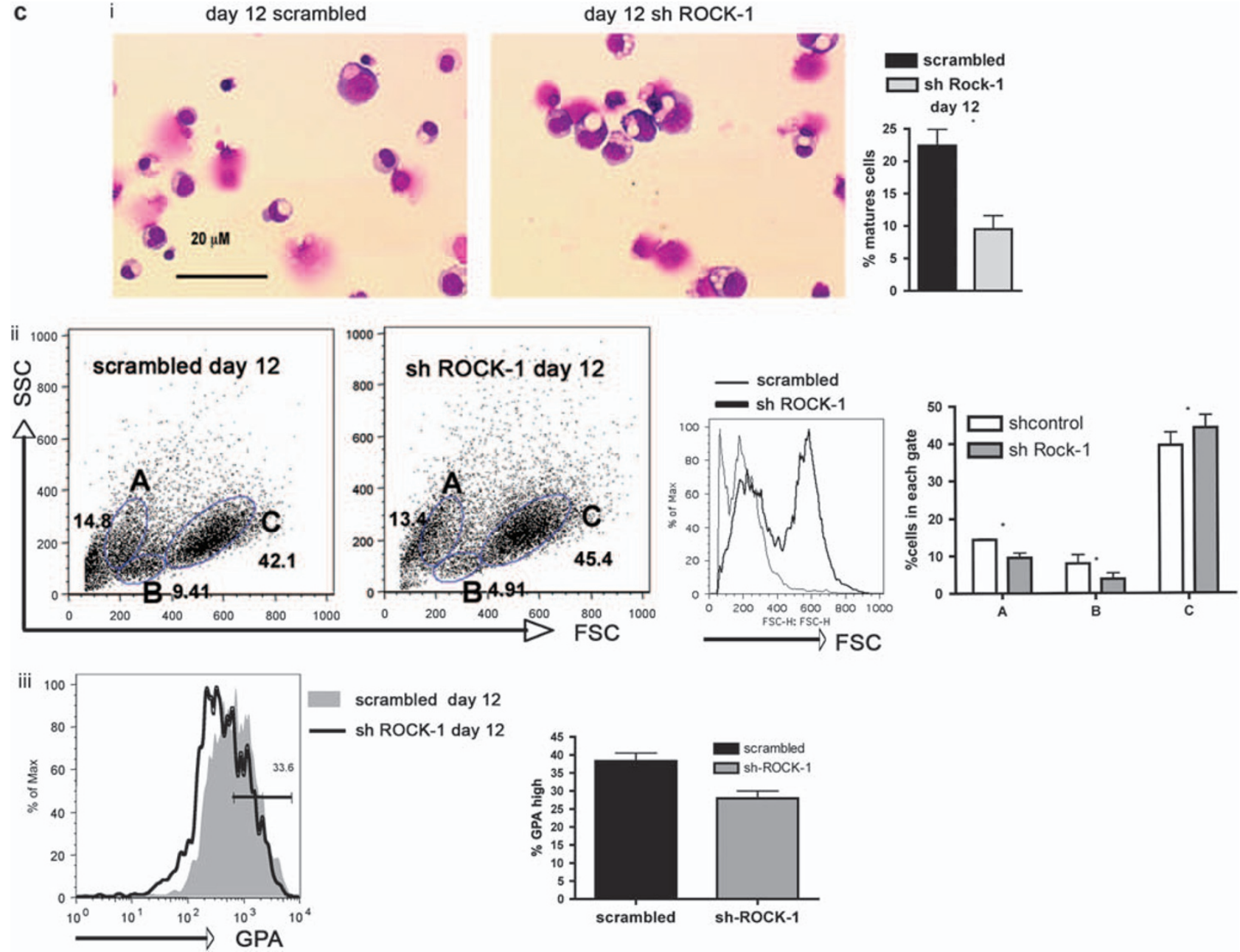

Figure 4 ROCK-1 inhibition impairs terminal differentiation. (a) CD36 cells were generated with a two-step amplification culture system as described in the continued presence of the ROCK inhibitor Y-27632. Data representatives of several experiments show that ROCK inhibition impairs erythroid terminal differentiation. Differentiation was evaluated at day 12 (i) by morphological analyses after May-Grünwald-Giemsa staining. The scale bar represents $20 \mu \mathrm{m}$. The percentage of matures cells (polychromatic and orthochromatic erythroblasts) was assessed by counting 300 cells in consecutive oil immersion fields $(N=12)$ (ii) by flow cytometric dot plots as described in Figure $3 \mathrm{~A}$ showing the relative number of cells in each region and FSC distribution histograms of a representative experiment. The graph indicates the mean percentage of cells in gates A, B and C. (b) The ROCK inhibitor Y-27632 was added from day 7 to 12. (i, ii) Differentiation was assessed as described in (a) ( $N=6$ ). (iii) Flow cytometric dot plots of CD36 cells at day 10 of the culture in the presence or not of the Y-27632 inhibitor added from day 0 to 10 or from day 7 to 10 in one representative experiment out of four. Cells were labeled for c-KIT and GPA as described in the Materials and Methods section. Two populations were defined: $\mathrm{C}-\mathrm{KIT}^{\text {neg }} \mathrm{GPA}^{\text {high }}$ and c-KIT ${ }^{\text {pos }} \mathrm{GPA}^{\text {int }}$ corresponding respectively to mature and immature cells. The relative number of cells in each region is indicated. The graph on the right panel indicates the mean percentage of cells in each region. (c) CD36 cells were infected with scrambled or ROCK-1 shRNA lentiviruses as described. (i, ii) Differentiation was assessed as described in (a) ( $N=5$ ). (iii) Flow cytometric GPA distribution histogram at day 12 of the culture from a representative experiment of scrambled and ROCK-1 shRNA-infected cultures. The gate corresponding to GPA ${ }^{\text {high }}$ cells is indicated. The graph on the right panel indicates the mean percentage of GPA ${ }^{\text {high }}$ cells in both cultures $(N=3)$

generated by caspase-3 cleavage. Treatment of the CD36 culture by QVD-OPH, another broad-spectrum inhibitor of caspases, at a dose of 50 or $200 \mu \mathrm{M}$ also abolished the Rock-1 cleavage and induced a dose-dependent decrease in terminal erythroid differentiation (Supplementary Information 2). This finding demonstrated that ROCK-1 is caspase-3 cleaved during the late step of erythropoiesis in non-apoptotic cells.

To determine whether a constitutively truncated form of ROCK-1 expressed before the onset of caspase activation could affect terminal differentiation, we transiently transfected CD36 cells at day 5 of the culture with a constitutively active mutant of ROCK-1: pCAG-Myc-ROCK-1 G1114opa $(\mathrm{ROCK}-1 \mathrm{DC})^{24}$ that contains a truncated auto-inhibitory domain. This experiment was performed without SCF to rule out any activation of ROCK-1 through Rho-induced phosphorylation.

For this purpose, cells were co-transfected with a mix of ROCK- $1 \Delta \mathrm{C}$ and a plasmid encoding GFP protein at a $4: 1$ ratio.

The percentage of cells expressing the ROCK- 1 mutant was determined after permeabilization by measuring Mycassociated fluorescence using flow cytometry. For this purpose, a gate was established above the level of autofluorescence seen in mock-transfected cells. The cells exhibiting Myc-associated fluorescence also exhibited GFP fluorescence (Figure 6bi). Therefore, differentiation was 
a
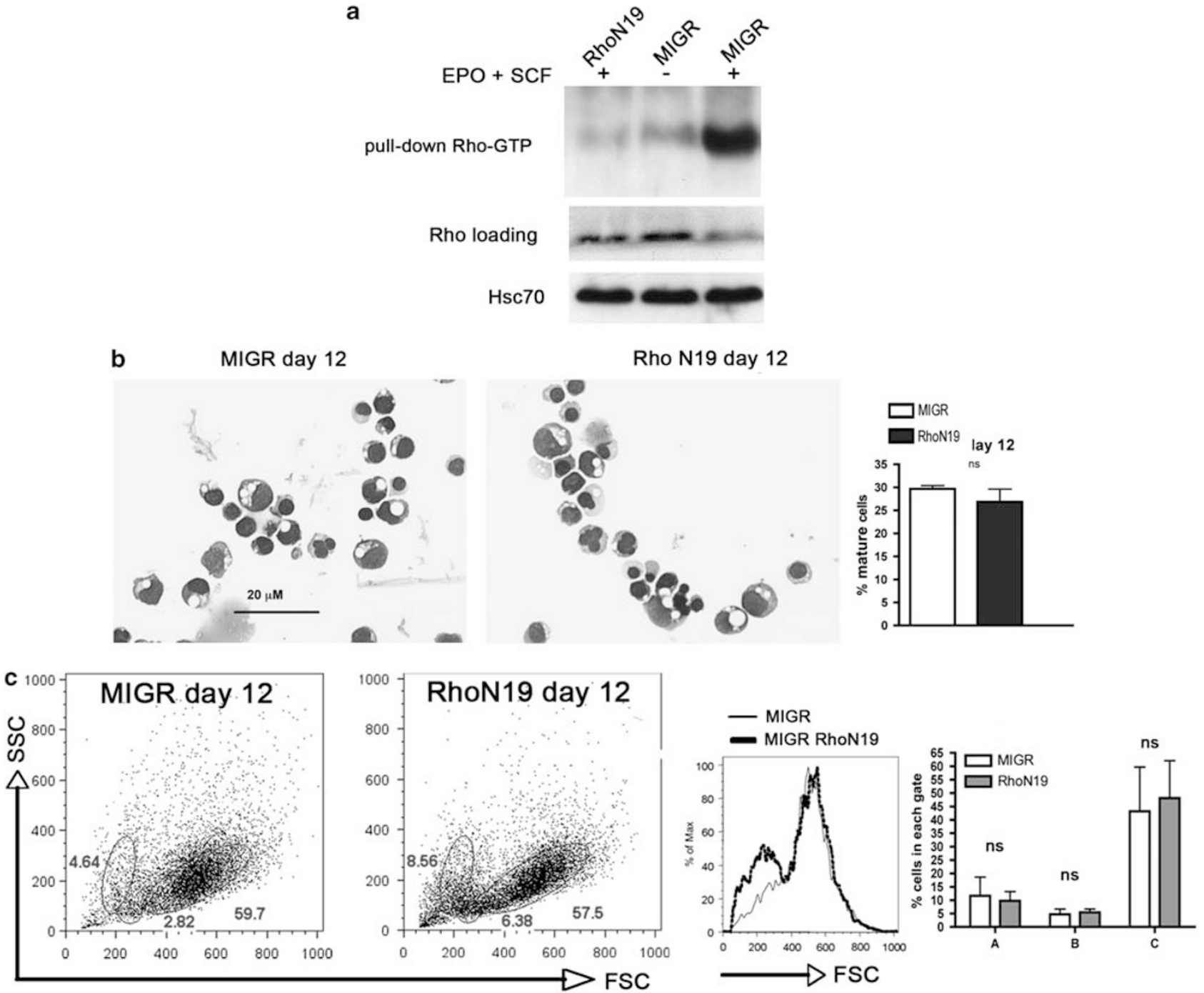

Figure 5 Rho is not involved in terminal differentiation. CD36 cells were infected with MIGR-GFP or MIGR-Rho-N19-GFP retroviruses as described ( $N=3$ ). (a) A pulldown Rho-GTP assay was performed at day 4 of the MIGR-GFP control or MIGR-Rho-N19-GFP infected CD36 culture after stimulation with EPO for 5 min or after cytokine deprivation as described. It shows that the GTPase activity is inhibited in MIGR-Rho-N19-GFP + infected cells. (b) Morphological analyses after May-Grünwald-Giemsa staining and (c) FSC-SSC density plots analyses as described in Figure 3A and FSC distribution histograms of a representative experiment both indicate that the dominantnegative Rho-N19 overexpression does not significantly affect terminal differentiation

assessed 24 and $48 \mathrm{~h}$ post-transfection by SSC-FSC FACS analyses on live GFP-positive cells. Cell distribution analysis indicated that the truncated ROCK-1 $\Delta \mathrm{C}$ construct significantly decreased cell size distribution $(7.4 \% \pm 0.8$ gating with mature cells versus $4.7 \% \pm 0.9$ in controls) (Figure 6bii). Differentiation was also assessed by cell-surface GPA expression. For this purpose, day 5 CD36 cells were transfected with the pCAG-Myc-ROCK-1 $\Delta$ C plasmid or with the empty vector. At 24 and $48 \mathrm{~h}$ post-transfection, cells were labeled for GPA then MYC after permeabilization and analyzed by flow cytometry. By $24 \mathrm{~h}$ post-transfection, the ratio of $\mathrm{GPA}^{\text {high }}$ erythroblasts was 2.2-fold increased in Myc-labeled ROCK-1 $\Delta \mathrm{C}$ transfected cells $(8.35 \pm 2.17$ versus $3.79 \pm 1.60$ in controls) and 2.7 -fold increased by $48 \mathrm{~h}(33.35 \pm 2.83$ versus $12.33 \pm 0.62$ in controls) (Figure $6 c$ ). These results indicated that the truncated ROCK- $1 \Delta \mathrm{C}$ construct accelerated maturation. Taken together, our data demonstrate that ROCK-1 is activated through an SCF-independent mechanism, through caspase-induced cleavage, to allow erythroblast terminal maturation.

ROCK-1 is the main MLC2-regulating kinase. One major role of the Rho/ROCK pathway is to regulate actomyosinbased contractility by modifying the MLC2 phosphorylation status. We analyzed the expression of total MLC2 and p-MLC2 (Ser 19) on CD36 + cells at serial time intervals. The level of MLC2 decreased at the end of the CD36 culture (Figure 6a). To investigate whether or not ROCK was involved in MLC2 phosphorylation, western blot analyses were performed on whole-cell lysates of the Y-27632-treated and control cultures at various times. At day 10, to discriminate differentiation induced from apoptotic MLC2 phosphorylation, annexin $\mathrm{V}$ - and $\mathrm{Pl}$-positive cells were excluded by cell sorting before cell lysis. MLC2 
phosphorylation was strongly inhibited by the Y-27632 inhibitor throughout the differentiation process (Figure $7 \mathrm{~b}$ ). Similar results were obtained after selective inhibition of ROCK-1 (Figure 7c) showing that ROCK-1 is the main MLC2-regulating kinase in erythroid cells. To determine whether MLC2 activation is Rho-independent in the late stage of differentiation, MLC2 phosphorylation was assessed at day 10 of the CD36 culture in which Rho activity was inhibited. For this purpose, the level of MLC2 phosphorylation was determined after annexin $\mathrm{V}$ - and PI-positive cell exclusion by cell sorting following a 24-h treatment with $5 \mu \mathrm{g} / \mathrm{ml}$ and $10 \mu \mathrm{g} / \mathrm{ml}$ of a cell penetrating form of the Clostridium Botulinum toxin C3, which induced a dosedependent inhibition of Rho GTPase activity (data not shown). As expected in our culture system in which some immature cells, which are Rho dependent, are still present at the end of the culture, a weak inhibition of MLC2 phosphorylation was observed with C3 transferase treatment, but this inhibition was weak compared with Y-27632 treatment as shown by analysis of the p-MLC2 : HSC70 ratio (Figure 7d).

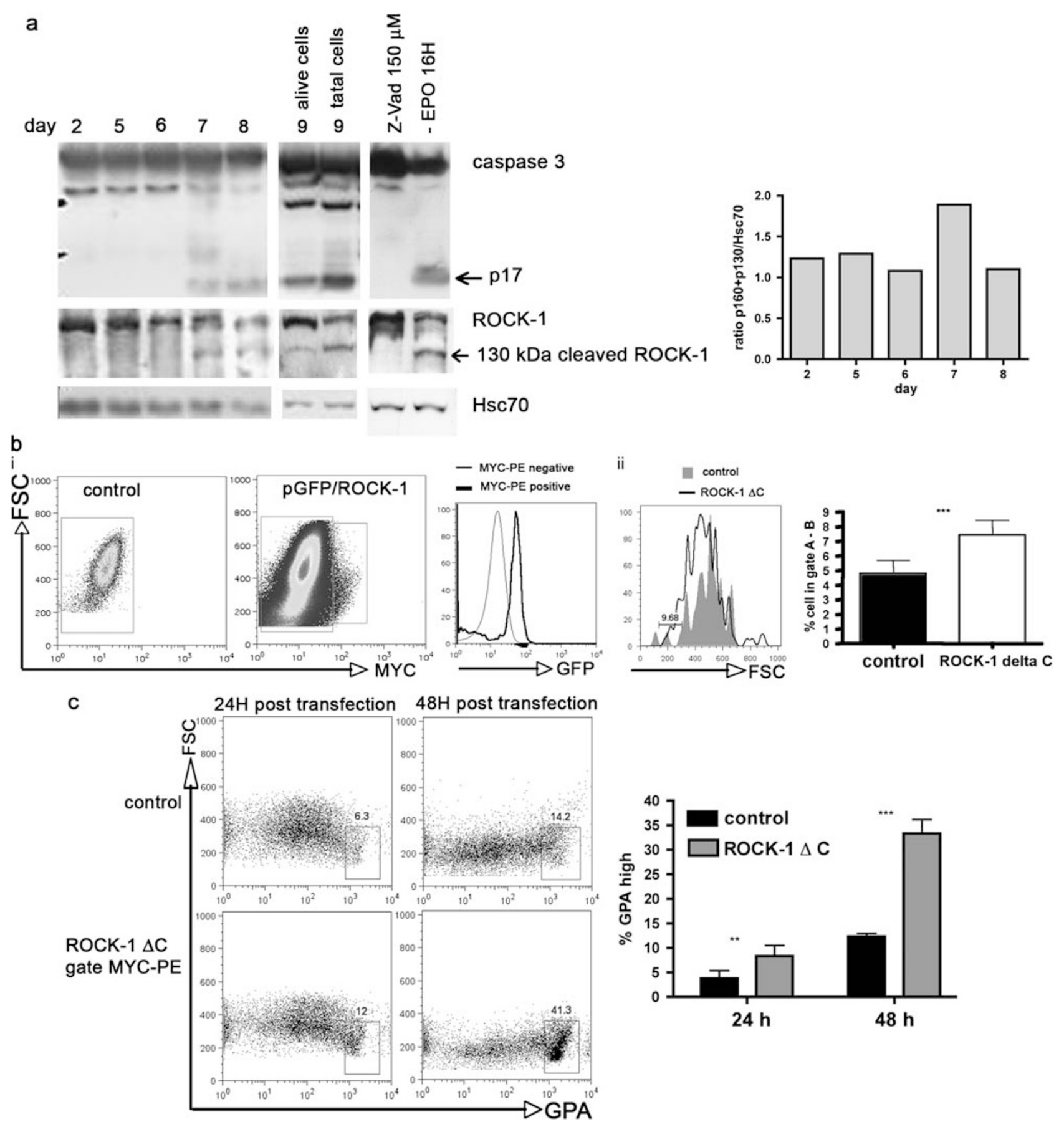


Therefore, we could conclude that MLC2 phosphorylation occurs independently of Rho via caspase-activated ROCK-1.

\section{Discussion}

Terminal erythroid differentiation is characterized by a sequence of morphological changes that require transient caspase activation. These events are followed by nuclei
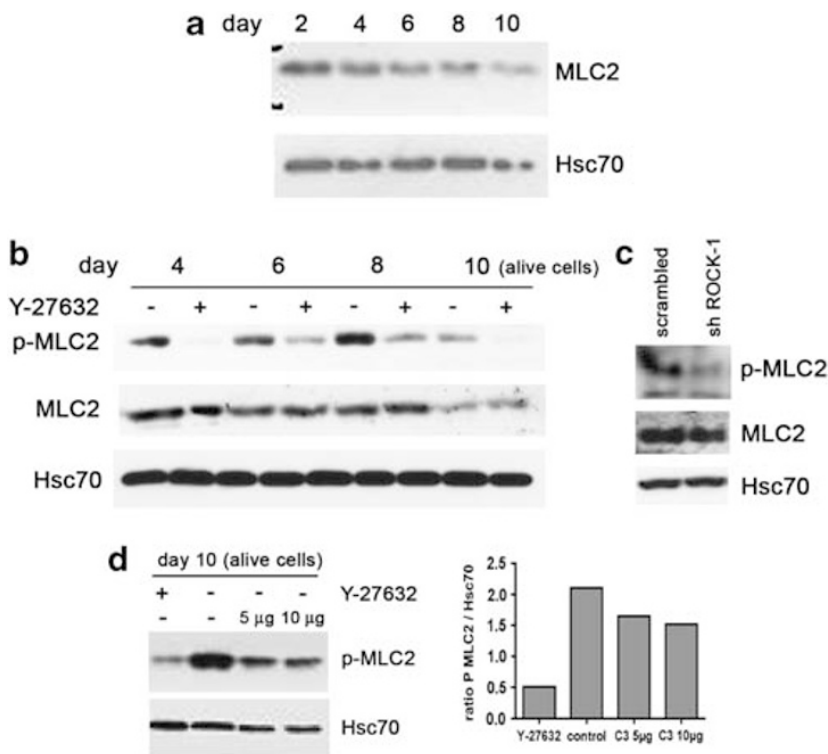

Figure 7 ROCK-1 is the main MLC2-regulating kinase. Erythroid cells were generated with a two-step amplification culture system as described. (a) Immunoblots were performed from whole-cell lysates for indicated times to detect MLC2. Control shows HSC70 levels. (b) To investigate the role of ROCK in MLC2 phosphorylation, the Y-27632 inhibitor was added to the culture for $24 \mathrm{~h}$ before cell lysis. At day 10, to discriminate apoptotic from differentiating cells, lysates were made after annexin V-and PI-positive cell exclusion by cell sorting (alive cells). Immunoblots detecting p-MLC2, MLC2 and HSC70 as loading control. (c) A CD34 culture was infected by ROCK-1 shRNA or scrambled lentiviruses and cultured as described. Immunoblots were performed at day 9 of the culture to detect p-MLC2, MLC2 and HSC70 as loading control. (d) At day 9, C3 transferase at a dose of 5 or $10 \mu \mathrm{g} / \mathrm{ml}$ was added to the culture for $24 \mathrm{~h}$ and annexin V-, PI-positive cells (alive cells) were excluded before cell lysis. Immunoblots detecting p-MLC2 and HSC70 as loading control are shown. Western blot quantification shows the P-MLC2/HSC70 ratio extrusion, which involves a profound reorganization of the cytoskeleton. We demonstrate here that the Rho effector protein ROCK-1 is required for terminal maturation occurring after the onset of caspase activation. At this stage, we show that Rho is not required, which is in agreement with reduced Rho expression at the end of differentiation. Late erythropoiesis can be characterized in successive stages with respect of cytokine dependency. First, early CFU-E express both c-KIT and EPO-R, the ligands of which are required for survival and proliferation. Then, basophilic erythroblasts downregulate C-KIT, after which caspases are transiently activated, inducing cleavage of selected substrates. c-KIT expression, which is critical for activation of the Rho/ROCK pathway, is lost at the end of erythroid differentiation, but this could be overcome by caspase-3-induced ROCK-1 cleavage. This phenomenon allows terminal maturation of erythroblasts independently of SCF signaling. This is confirmed by our results showing that a constitutively truncated construct of ROCK-1 expressed before the onset of caspase activation accelerated terminal maturation. This truncated form exhibits a higher intrinsic kinase activity ${ }^{24,25}$ that could be required for terminal maturation. However, terminal differentiation, which is inhibited in the presence of a caspase inhibitor, ${ }^{4}$ could not be rescued by expressing the constitutively cleaved form of ROCK-1 (data not shown) suggesting that other caspase targets are involved in terminal maturation.

Rock-1-/- newborn mice exhibit developmental defects in the eyelid and the ventral body wall closure. ${ }^{27}$ No obvious anemia was described; nevertheless, erythroblast development has not been investigated in these mice ${ }^{28}$ and compensatory changes in other kinases including MLCK, a caspase-3 target during apoptosis, ${ }^{29}$ cannot be excluded.

ROCK-1 could be involved in erythroid terminal maturation at least in part through contractility control by regulating MLC2 phosphorylation. In the erythroblast, myosin II could function in an actomyosin contractile apparatus responsible for maintaining a normal cell shape during cell condensation. Rho/ROCK-1 pathway has been shown to be involved in other differentiation systems, including proplatelet formation through MLC2 phosphorylation, ${ }^{30}$ and keratinocyte differentiation through stratification and enlargement of cell size. ${ }^{31}$ Recent findings also define a cytoskeleton-independent function for ROCK in regulating morphogenesis and cell size

Figure 6 ROCK-1 is activated by caspase-3 cleavage. (a) On the left panel: immunoblots of a 12\% acrylamide gel were performed from whole-cell lysates from CD 36 cells cultured as described for the indicated times in the presence of cytokines or in the presence of the caspase inhibitor z-VAD-fmk at $150 \mu \mathrm{M}$, or overnight deprived of growth factors (-EPO 16H) at day 9. The blots detect the 32-kDa procaspase-3 and its 17-kDa cleavage product (p17), showing the onset of caspase activation at day 7-8. The same lysates were loaded on an $8 \%$ acrylamide gel to detect ROCK-1 (160-kDa) and its $130-\mathrm{kDa}$ cleavage product. HSC70 is shown as a loading control. At day 9 , to discriminate apoptotic from differentiating cells, lysates were performed before (nine total cells) or after annexin $\mathrm{V}$ and PI-positive cell exclusion by cell sorting (nine alive cells). On the right panel, western blot quantification showing the ROCK-1 p160 + p130/HSC70 ratio. (b) (i) CD36 cells were mock-transfected (control) or transfected with a mix of pCAG-MycROCK-1 G1114opa (ROCK-1 $\triangle \mathrm{C}$ ) and pGFP at a $4: 1$ ratio. At $24 \mathrm{~h}$ post-transfection, cells were fixed, permeabilized, and Myc-associated or GFP fluorescence was analyzed by flow cytometry using the 9E10-PE mAb (Santa Cruz sc-40). Gates were established to analyze Myc-associated fluorescence, which was negative in mock-transfected cells (left panel) and positive in pGFP + ROCK-1 $\Delta \mathrm{C}$ transfected cells (middle panel). Histogram (right panel) shows that cells exhibiting Myc-associated fluorescence also exhibited GFP fluorescence. One representative out of six experiments is shown. (ii) CD36 cells were transiently transfected as described in bi. Forward scatter distribution histograms overlays of ROCK-1 $\triangle \mathrm{C}+$ pGFP and pGFP (control) transfected cells, assessed $48 \mathrm{~h}$ post-transfection on GFP-positive cells. The gate corresponded to mature cells (regions $A$ and $B$ as defined in Figure $3 \mathrm{~A}$ ). Results are the average of five experiments performed in triplicate. (c) Day 5 CD36 cells were transfected with the pCAG-Myc-ROCK-1 $\Delta$ C plasmid or with the empty vector as described in the Materials and Methods section. Differentiation was assessed 24 and $48 \mathrm{~h}$ post-transfection by cell-surface GPA expression from the MYC-positive population selected from pCAG-Myc-ROCK-1 $\triangle \mathrm{C}$ transfected cells and compared with controls. Representative flow cytometric analysis of one experiment assessed 24 and $48 \mathrm{~h}$ post-transfection of MYC-positive cells from pCAG-Myc-ROCK-1 $\Delta$ C transfected cells in respect to GPA and size (FSC), compared with controls $(N=4)$. A region corresponding to $\mathrm{GPA}^{\text {high }}$ cells was defined and the relative number of cells in this region is indicated. The graph on the right panel indicating the mean percentage of GPA ${ }^{\text {high }}$ cells in this region shows that the truncated ROCK-1 $\Delta \mathrm{C}$ construct accelerated maturation 
through insulin/IGF signaling. ${ }^{32}$ Interestingly, ROCK activity was also shown to be a component of the switch in the adipogenesis/myogenesis fate. ${ }^{33,34}$ Thus, we cannot exclude that in addition to its role in mediating MLC2 phosphorylation, ROCK-1 may have another function required for terminal erythroid differentiation. Our data provide another evidence that ROCK is a critical mediator of cell differentiation.

Recent analyses have provided substantial evidence that apoptotic caspases have important functions in the differentiation of various cell types. Keratinocyte cornification involves caspase-14-mediated cleavage of profilaggrin, ${ }^{35,36}$ and lens fiber epithelial cells are characterized by complete removal of the nucleus. ${ }^{37}$ Another type of anucleate cell, platelets, is produced by megakaryocytes in which selected substrates are cleaved by compartmentalized activation of caspase-3. ${ }^{38}$ Moreover, myoblast to myotube differentiation, which involves caspase-3-mediated cleavage of the kinase MST1, shares other features with apoptosis such as disassembly and reorganization of the actin fiber. ${ }^{39}$ Nevertheless, little is known concerning the identity of caspases substrates involved in differentiation and the exact requirement for caspase activity in these systems. We show here that caspase-3 activation in basophilic erythroblasts, cells in which C-KIT receptor expression is lost, allows constitutive activation of ROCK-1, one of their substrates. We could therefore propose a model in which ROCK is Rho-dependent until the basophilic stage, whereas in the later steps of differentiation, when Rho is no longer activated by SCF signaling, caspase-3activated ROCK-1 allows terminal maturation. Further exploration of caspase targets in the future will shed light on the mechanism of erythroid differentiation as well as on other systems in which caspases are activated for cell differentiation

\section{Materials and Methods \\ Reagents and antibodies. Y-27632 and blebbistatin were from Calbiochem (Darmstadt, Germany). Z-VAD-fmk was from Alexis Biochemicals (San Diego, CA, USA). The cell-permeable Rho inhibitor C3 transferase was from Cytoskeleton (Denver, CO, USA). The following antibodies were used for western blots: anti- MLC2 (FL-172) from Santa Cruz (Santa Cruz, CA, USA), anti-phospho-MLC2 monoclonal antibody (mAb) from Cell Signaling (Danvers, MA, USA), anti-ROCK-1 $\mathrm{mAb}$ from BD Biosciences (San Jose, CA, USA), anti-Rho mAb from Cytoskeleton, anti-HSC70 from Stressgen (Victoria, BC, Canada), anti-caspase 3 from Neomarker (Fremont, CA, USA), c-KIT and phospho-c-KIT from Cell Signaling.}

In vitro generation of erythroid cells. Umbilical cord blood units from normal full-term deliveries were obtained after informed consent of the mothers from the Obstetrics Unit of Hôpital Necker-Enfants Malades. Erythroid cells were generated with a two-step amplification culture system as previously described ${ }^{4}$ with the following modification: because $20-35 \%$ of the cells were GPA + after the first step of CD34 + expansion, to better synchronize the culture, we isolated $\mathrm{CD} 36+\mathrm{GPA}^{-}$progenitors at the end of the first step. For this purpose, cells were stained with anti-CD36-APC mAb (BD Pharmingen, San Diego, CA, USA) and antiglycophorin A- phycoerythrin (PE) mAb (BD Pharmingen) and the CD36 + GPA fraction was purified by cell sorting (Facs ARIA Becton Dickinson, Franklin Lakes, NJ, USA) (day 0). These cells were subsequently cultured for 10-12 additional days in the presence of IL-3, SCF and EPO. To investigate the role of ROCK during terminal differentiation, the ROCK inhibitor Y-27632 was added at a concentration of $10 \mu \mathrm{M}$ in the second step of the culture and the cells were diluted every day with fresh medium without or with Y-27632.

Cell proliferation, differentiation and apoptosis assay. Cell proliferation was assessed by counting cells every day after Trypan blue dye exclusion staining. Apoptosis was assessed by annexin V binding and PI or 7AAD staining.

Differentiation was assessed by morphological analysis after May-GrünwaldGiemsa coloration. Cells were examined under a Leica (Wetzlar, Germany) DMRB microscope with a PLFluotar 40X oil objective. The number of mature cells (polychromatic and orthochromatic erythroblasts) was assessed in each experiment by counting 300 cells in consecutive oil immersion fields and is expressed as a percentage of total cells.

Differentiation was also evaluated after dead cell and debris exclusion by flow cytometric analysis, which allowed quantitative assessment of the maturation stage of differentiating erythroblasts. Terminal maturation is characterized by morphological changes including progressive cell size reduction, chromatin condensation and nucleus extrusion. Forward light scatter and side scatter FACS analysis indirectly measures changes in cell volume and structure. After dead cells exclusion, we could define three populations $A, B$ and $C$ in differentiating CD36 cells (see results Figure $3 A$ ). The relative number of cells in each population varied between the onset of caspases activation at day 8 and 12. Cells from each population were sorted and analyzed morphologically. Proerythroblasts were identified in gate $\mathrm{C}$, polychromatic and orthochromatic erythroblasts in gate B and a mix of orthochromatic erythroblasts, reticulocytes and nuclei were present in gate A. Erythroid differentiation was also evaluated by flow cytometry after double labeling with PE-conjugate anti-GPA (BD Pharmingen) antibody and APC-conjugate anti-c-KIT (BD Pharmingen) antibody.

Western blot analysis. For detection of ROCK, cells were lysed buffer in Triton buffer (50 mM Tris pH7.5, 1\% Triton X-100, $100 \mathrm{~mm} \mathrm{NaCl,} 10 \mathrm{~mm}$ tetrasodium pyrophosphate) and $10 \mathrm{~mm} \mathrm{NaF}, 1 \mathrm{~mm}$ EDTA, $1 \mathrm{~mm}$ NaV, $1 \mathrm{~mm}$ EGTA, $1 \mathrm{~mm}$ phenylmethylsulphonyl fluoride and $1 \mu \mathrm{g} / \mathrm{ml}$ each of aprotinin, leupeptin and pepstatin. For detection of Rho, cells were lysed according to the protocol of the Rho activation assay kit. For detection of caspases, MLC2 and c-KIT, cells were lysed in Laëmmli buffer ( $60 \mathrm{~mm}$ Tris pH6.8, 2\% SDS). Protein concentration was assessed using the BCA kit (Pierce, Rockford, IL, USA). Proteins were loaded at $50 \mu \mathrm{g}$ per well and were separated by SDS-PAGE. After transfer to a polyvinylidene difluoride membrane (GE Healthcare, Saclay, France) and blocking for at least $1 \mathrm{~h}$ in PBS, $5 \%$ non-fat milk and $0.1 \%$ Tween 20 , blots were hybridized and proteins were visualized by enhanced chemiluminescence (Pierce).

To investigate the role of ROCK or Rho in MLC2 phosphorylation, Y-27632 $(10 \mu \mathrm{M})$ or $\mathrm{C} 3(5$ and $10 \mu \mathrm{g} / \mathrm{ml})$ respectively, was added to the culture for $24 \mathrm{~h}$. At the end of the culture (day 10), cells were stained with annexin V-APC and PI, and dead cells were excluded by cell sorting before lysis.

Rho pull-down assay. Pull-down assays were performed with a Rho activation assay kit (Cytoskeleton). To analyze Rho activity, CD36 + GPA - cells isolated by cell sorting were grown in serum-free medium with IL3, SCF and EPO. At day 4 and 10 of the culture (before and after the onset of caspases activation), cells were washed with serum-free medium and cytokine-deprived for $8 \mathrm{~h}$. Cells were then stimulated with EPO $(10 \mathrm{U} / \mathrm{ml})$, SCF $(100 \mathrm{ng} / \mathrm{ml})$ or SCF + EPO for 5 to $30 \mathrm{~min}$. Cells were collected, washed in PBS at $4{ }^{\circ} \mathrm{C}$ and manipulated according to the protocol of the Rho activation assay kit. Pull-down assays were performed with $300 \mu \mathrm{g}$ of protein.

shRNA ROCK-1 lentiviral production. Four shRNAmir constructs targeting the human ROCK-1 sequence, cloned in the pGIPZ lentiviral vector (Open Biosystems, Huntsville, AL, USA) were tested and the two that knockdown ROCK-1 protein in western blot, (nucleotides 2428-2450 Open Biosystems V2LHS_70607 and nucleotides 2358-2380 Open Biosystems V2LHS_70609) were used in this study. pGIPZ lentiviruses were produced by 293T cells co-transfected by pCMV-Gag-Pol and pCMV-VSV-G plasmids (Open Biosystems). Supernatants were collected 48 and $72 \mathrm{~h}$ after transfection, and were pooled and concentrated by ultracentrifugation. Virus stocked was kept frozen at $-70^{\circ} \mathrm{C}$.

Retroviral production. Retrovirus MIGR-GFP and the retrovirus expressing the dominant-negative form of Rho MIGR RhoA-N19, were produced as described. ${ }^{30}$

Erythroid cell infection. CD34 + cells isolated from cord blood were cultured for 5 days as described then infected by shRNA GIPZ lentiviruses or MIGR-GFP retroviruses. A second round of infection was performed $24 \mathrm{~h}$ later on changing to fresh medium with cytokines. After an additional $24 \mathrm{~h}$, cells 
were extensively washed in PBS and stained with the anti-CD36-APC mAb and anti-GPA-PE mAb. The CD36 + GPA ${ }^{-}$GFP + cell population was purified by cell sorting and cultured in serum-free medium in the presence of IL3 + SCF + EPO.

Erythoid cells transient transfection. Transient transfections were performed with $3 \times 10^{6} \mathrm{CD} 36$ cells cultured for 5 days in the presence of IL3, SCF and EPO by nucleoporation in $100 \mu \mathrm{l}$ of nucleofector solution (Amaxa Biosystems, Cologne, Germany) with $2.5 \mu \mathrm{g}$ of pcDNA-GFP or with $2.5 \mu \mathrm{g}$ of a mix of pcDNA-GFP and constitutively truncated ROCK-1 ${ }^{24}$ (pCAG-Myc-ROCK-1 G1114opa kindly provided by $\mathrm{Dr}$ Michael Olson) at a 1:4 ratio. After transfection, CD36 cells were cultured without SCF to reduce proliferation. To determine the percentage of GFP-positive cells exhibiting Myc-associated fluorescence, cells were fixed, permeabilized, and labeled for Myc expression using the 9E10-PE mAb (Santa Cruz sc-40). Differentiation was assessed 24 and $48 \mathrm{~h}$ after nucleoporation by analyzing FSC-SSC cell distribution of GFP-positive cells. Differentiation was also analyzed by cell-surface GPA expression of cells exhibiting Myc-associated fluorescence. For this purpose, day $5 \mathrm{CD} 36$ cells were transfected as described with $2 \mu \mathrm{g}$ of the pCAG-Myc-ROCK-1 G1114opa plasmid or $2 \mu \mathrm{g}$ of the empty vector. At 24 and $48 \mathrm{~h}$ after nucleoporation, the transfected cells were cell-surface labeled with APC-conjugate anti-GPA (BD Pharmingen), then fixed, permeabilized and labeled for Myc expression with the 9E10-PE mAb and analyzed with flow cytometry.

Statistical analyses. Analysis was performed using Prism software (GraphPad Software Inc, La Jolla, CA, USA) and paired $t$-tests were used for the statistical analyses. Asterisks indicate significant differences: ${ }^{*} P$-value $<0.05,{ }^{\star *} P$ value $<0.01$ and ${ }^{* *} P$-value $<0.00$.

\section{Conflict of interest}

The authors declare no conflict of interest.

Acknowledgements. We thank Professor Y Dumez, Professor Y Ville and nurses of the Obstetric Unit (Hospital Necker-Enfants Malades) for providing us with cord blood samples. We thank Dr M Olson (Beatson Institute for Cancer Research) for providing us with the constitutive ROCK-1 construct. We also thank $\mathrm{C}$ Cordier and $\mathrm{J}$ Megret (Institut Necker) for cell sorting and JB Arlet for critical reading of the manuscript. This work was supported by grant from ANR Blanc (W V and $\mathrm{O} \mathrm{H}$ ), Cancéropole lle de France, Ligue Nationale contre le Cancer (équipe labellisée LNCC). We also thank Cyril Mongin's family and friends association.

1. Koury ST, Koury MJ, Bondurant MC. Morphological changes in erythroblasts during erythropoietin-induced terminal differentiation in vitro. Exp Hematol 1988; 16: 758-763.

2. Cantor $A B$, Orkin SH. Transcriptional regulation of erythropoiesis: an affair involving multiple partners. Oncogene 2002; 21: 3368-3376.

3. Weiss MJ, Orkin SH. Transcription factor GATA-1 permits survival and maturation of erythroid precursors by preventing apoptosis. Proc Natl Acad Sci USA 1995; 92: 9623-9627.

4. Zermati Y, Garrido C, Amsellem S, Fishelson S, Bouscary D, Valensi F et al. Caspase activation is required for terminal erythroid differentiation. J Exp Med 2001; 193: 247-254.

5. Kolbus A, Pilat S, Husak Z, Deiner EM, Stengl G, Beug H et al. Raf-1 antagonizes erythroid differentiation by restraining caspase activation. J Exp Med 2002; 196: 1347-1353.

6. Carlile GW, Smith DH, Wiedmann M. Caspase-3 has a nonapoptotic function in erythroid maturation. Blood 2004; 103: 4310-4316.

7. Lui JC, Kong SK. Erythropoietin activates caspase-3 and downregulates CAD during erythroid differentiation in TF-1 cells - a protection mechanism against DNA fragmentation. FEBS Lett 2006; 580: 1965-1970.

8. Ribeil JA, Zermati Y, Vandekerckhove J, Cathelin S, Kersual J, Dussiot M et al. Hsp70 regulates erythropoiesis by preventing caspase-3-mediated cleavage of GATA-1. Nature 2007; 445: 102-105.

9. Broudy VC. Stem cell factor and hematopoiesis. Blood 1997; 90: 1345-1364.

10. Richmond TD, Chohan M, Barber DL. Turning cells red: signal transduction mediated by erythropoietin. Trends Cell Biol 2005; 15: 146-155.

11. Muta K, Krantz SB, Bondurant MC, Dai CH. Stem cell factor retards differentiation of norma human erythroid progenitor cells while stimulating proliferation. Blood 1995; 86: 572-580.
12. Uoshima N, Ozawa M, Kimura S, Tanaka K, Wada K, Kobayashi Y et al. Changes in c-Kit expression and effects of SCF during differentiation of human erythroid progenitor cells. Br J Haematol 1995; 91: 30-36.

13. Muta K, Krantz SB, Bondurant MC, Wickrema A. Distinct roles of erythropoietin, insulin-like growth factor I, and stem cell factor in the development of erythroid progenitor cells. J Clin Invest 1994; 94: 34-43.

14. Etienne-Manneville S, Hall A. Rho GTPases in cell biology. Nature 2002; 420: 629-635.

15. Schwartz M. Rho signalling at a glance. J Cell Sci 2004; 117: 5457-5458.

16. Raftopoulou M, Hall A. Cell migration: Rho GTPases lead the way. Dev Biol 2004; 265: 23-32.

17. Mulloy JC, Cancelas JA, Filippi MD, Kalfa TA, Guo F, Zheng Y. Rho GTPases in hematopoiesis and hemopathies. Blood 2010; 115: 936-947.

18. Kalfa TA, Pushkaran S, Mohandas N, Hartwig JH, Fowler VM, Johnson JF et al. Rac GTPases regulate the morphology and deformability of the erythrocyte cytoskeleton. Blood 2006; 108: 3637-3645.

19. Kalfa TA, Pushkaran S, Zhang X, Johnson JF, Pan D, Daria D et al. Rac1 and Rac2 GTPases are necessary for early erythropoietic expansion in the bone marrow but not in the spleen. Haematologica 2010; 95: 27-35.

20. Ji P, Jayapal SR, Lodish HF. Enucleation of cultured mouse fetal erythroblasts requires Rac GTPases and mDia2. Nat Cell Biol 2008; 10: 314-321.

21. Riento K, Ridley AJ. Rocks: multifunctional kinases in cell behaviour. Nat Rev Mol Cell Biol 2003; 4: 446-456.

22. Kureishi Y, Kobayashi S, Amano M, Kimura K, Kanaide H, Nakano T et al. Rho-associated kinase directly induces smooth muscle contraction through myosin light chain phosphorylation. J Biol Chem 1997; 272: 12257-12260.

23. Amano M, Ito M, Kimura K, Fukata Y, Chihara K, Nakano T et al. Phosphorylation and activation of myosin by Rho-associated kinase (Rho-kinase). J Biol Chem 1996; 271: 20246-20249.

24. Coleman ML, Sahai EA, Yeo M, Bosch M, Dewar A, Olson MF. Membrane blebbing during apoptosis results from caspase-mediated activation of ROCK I. Nat Cell Biol 2001; 3 : 339-345.

25. Sebbagh M, Renvoize C, Hamelin J, Riche N, Bertoglio J, Breard J. Caspase-3-mediated cleavage of ROCK I induces MLC phosphorylation and apoptotic membrane blebbing. Nat Cell Biol 2001; 3: 346-352.

26. Croft DR, Olson MF. The Rho GTPase effector ROCK regulates cyclin A, cyclin D1, and p27Kip1 levels by distinct mechanisms. Mol Cell Biol 2006; 26: 4612-4627.

27. Olson MF. Applications for ROCK kinase inhibition. Curr Opin Cell Biol 2008; 20: 242-248.

28. Wang HW, Liu PY, Oyama N, Rikitake Y, Kitamoto S, Gitlin J et al. Deficiency of ROCK1 in bone marrow-derived cells protects against atherosclerosis in LDLR-/- mice. Faseb J 2008; 22: 3561-3570.

29. Petrache I, Birukov K, Zaiman AL, Crow MT, Deng H, Wadgaonkar R et al. Caspase-dependent cleavage of myosin light chain kinase (MLCK) is involved in TNF-alpha-mediated bovine pulmonary endothelial cell apoptosis. Faseb $\mathrm{J}$ 2003; 17 : 407-416.

30. Chang Y, Aurade F, Larbret F, Zhang Y, Le Couedic JP, Momeux L et al. Proplatelet formation is regulated by the Rho/ROCK pathway. Blood 2007; 109: $.4229-4236$

31. Liebig T, Erasmus J, Kalaji R, Davies D, Loirand G, Ridley A et al. RhoE Is required for keratinocyte differentiation and stratification. Mol Biol Cell 2009; 20: 452-463.

32. Sordella R, Classon M, Hu KQ, Matheson SF, Brouns MR, Fine B et al. Modulation of CREB activity by the Rho GTPase regulates cell and organism size during mouse embryonic development. Dev Cell 2002; 2: 553-565.

33. Sordella R, Jiang W, Chen GC, Curto M, Settleman J. Modulation of Rho GTPase signaling regulates a switch between adipogenesis and myogenesis. Cell 2003; 113: 147-158.

34. Noguchi M, Hosoda K, Fujikura J, Fujimoto M, Iwakura H, Tomita T et al. Genetic and pharmacological inhibition of Rho-associated kinase II enhances adipogenesis. J Biol Chem 2007; 282: 29574-29583.

35. Denecker G, Hoste E, Gilbert B, Hochepied T, Ovaere P, Lippens S et al. Caspase-14 protects against epidermal UVB photodamage and water loss. Nat Cell Biol 2007; 9: 666-674.

36. Denecker G, Ovaere P, Vandenabeele P, Declercq W. Caspase-14 reveals its secrets. J Cell Biol 2008; 180: 451-458.

37. Zandy AJ, Lakhani S, Zheng T, Flavell RA, Bassnett S. Role of the executioner caspases during lens development. J Biol Chem 2005; 280: 30263-30272.

38. De Botton S, Sabri S, Daugas E, Zermati Y, Guidotti JE, Hermine $\mathrm{O}$ et al. Platelet formation is the consequence of caspase activation within megakaryocytes. Blood 2002; 100: $1310-1317$.

39. Fernando P, Kelly JF, Balazsi K, Slack RS, Megeney LA. Caspase 3 activity is required for skeletal muscle differentiation. Proc Natl Acad Sci USA 2002; 99: 11025-11030.

\section{Supplementary Information accompanies the paper on Cell Death and Differentiation website (http://www.nature.com/cdd)}

